\title{
Socio-economic factors in stimulating agriculture in a crisis
}

\author{
Anzhela Namitulina ${ }^{1, *}$, Viktor Gorlov ${ }^{2,3}$, Irina Soklakova ${ }^{3,4}$, Elena Kuzmina ${ }^{5}$ and Diana \\ Ermilina $^{6}$ \\ ${ }^{1}$ Financial University under the Government of the Russian Federation, 125468 Moscow, Russian \\ Federation \\ ${ }^{2}$ Russian State University of Oil and Gas named I.M. Gubkin, 119991 Moscow, Russian Federation \\ ${ }^{3}$ Moscow State University of Management Moscow Government, Moscow, 107045, Russian Federation \\ ${ }^{4}$ Academy of management and production, 123007 Moscow, Russian Federation \\ ${ }^{5}$ State University of Management, 109542 Moscow, Russian Federation \\ ${ }^{6}$ Moscow Economic Institute, 123007 Moscow, Russian Federation
}

\begin{abstract}
Agriculture faces a series of challenges, i.e. guaranteeing national food security, increasing farmer's income and reducing the adverse effects on environment and human health associated with the use of fertilizers and biocides. At the same time, the availability of resources (e.g. agricultural land) decreases. The objective of this study in this article is to operationalize a methodology to assess the effectiveness of new crop and livestock technologies in attaining rural development goals. Cropping systems, quantified in terms of inputs and outputs, are used as the smallest unit of analysis in this study. A land use model, based on linear programming techniques, is used to assess the contribution of alternative cropping systems to rural development goals. Results of this study contribute to the formulation of agricultural policies and a research agenda aiming at stimulating rural development.
\end{abstract}

\section{1 lintroduction}

The main aim of this study is to develop dynamic simulation models that can help to explore the consequences of various farm management strategies at the farm level and of agricultural policies at the regional level. The main indicators that are monitored pertain to soil fertility, farm income, food security, land use pattern and distribution of farm types. The study in this article can be divided in four parts: introduction, model, empirical results and analysis and conclusion. The model of economic in ensuring sustainable development of agriculture. The advantage of this model is that it combines the concerns of ecology and a broadly defined political economy, allowing the explanation of various kinds of resource exploitation, social and ecological degradation and impacts of agricultural technology and other interventions. According to the view of political ecology, ecological degradation should not only be seen as a result of technology, but also as a result of the socioeconomic environment. On the other hand, ecological degradation may also force the people, who

* Corresponding author: z.anzhela@bk.ru 
directly caused it, to apply technology that deteriorates the situation further, because the environment in which they act does not provide them with incentives to improve their technology. So, people's actions are explained by their ecological as well as their political economic, social and institutional environment. This however is still not sufficient for an operationalisation of the concept of sustainability as the question remains what the performance criteria and their target values are. In this article a distinction is made between man-made capital stock (e.g. machines, factories, roads but also knowledge and skills) and natural capital stock (e.g. soil fertility, forests, fossil energy resources). According to the weak sustainability view, the total capital stock is not allowed to decline, but it is allowed to substitute natural capital stock for man-made capital stock (e.g. natural soil fertility for fertilizers). Strong sustainability is achieved when natural capital as well as manmade capital do not decline but substitution within both categories is allowed. Whether one should strive for weak or strong sustainability may also depend on the situation. In poor regions, where access to fertilizers is limited, it may be impossible to substitute loss of natural fertility by fertilizers [4]. Under such conditions it may be more important to follow a policy that aims at strong sustainability than in rich countries e.g. by putting more emphasis on agroforestry, water harvesting techniques and socially relevant technology

\section{Methods analysis and assumptions}

In modern conditions of market economically more prosperous regions favours diversification towards more profitable products. Although the demand for food increases and market chain prospects are favourable, the area of arable land decreases due to urbanization and industrialization by about $17 \%$ per year. The agricultural labour force declines, because part of the rural population, especially the young and better educated, migrates to urban centres. Against this background of fast and unprecedented economic developments, presenting severe challenges to agriculture, agro-ecosystems are characterized from a biophysical and socio-economic point of view, and it is necessary to create a model of the economy taking into account the current developments and challenges. Guided by the selective values, the datasets and the breakdown of sustainable criteria into variables, different modelling procedures and methods were selected. Derived from the analyses were combined socio-economic and developmental attributes. A majority of the problems related to sustainability identified in the research area were based on environmental indicators stemmed from socio-economic factors. Therefore, to assess and understand these complex interactions, the study adopted an analytical regime and makes use of information that links features and phenomena at the study area to their respective locations and relationships. In the course of the research, empirical research methods were used, strengths, weaknesses and major threats of current systems are identified, and opportunities to improve current systems improvements are explored of agriculture. The model of economic seeks to achieve techniques for modelling and optimizing agriculture based on established internal model control theory. This article is organized as follows: first, analysis of economic factors affecting the natural resource base and agricultural land. Second, given a model agro-ecosystems are characterized and analysed its features. Then, crop management is analysed. On the basis of these analyses, a SWOT (strengths, weaknesses, opportunities and threats) analysis is performed. Last, conclusions are presented. 


\section{Model construction}

\subsection{Current practice for agriculture optimization}

The model consists of a set of equations (the basic model) and sets of parameters, representing the basic characteristics of the various farm types, such as household size, cultivated area, crop rotation, cultivation practices. The economic model divides fertile land into parcels, belonging to a particular soil type. These soil types have fixed as well as variable characteristics: texture is fixed, but soil depth, organic matter content, organic $\mathrm{N}$ and $\mathrm{P}$, inorganic $\mathrm{P}$ and $\mathrm{pH}$ may change per field during the simulation period. The simulations are carried and show effects of farm management during this period. By changing one or more parameters, it is possible to compare the effects of different management strategies. The model consists of a number of subsystems: the cropping subsystem, the soil subsystem.

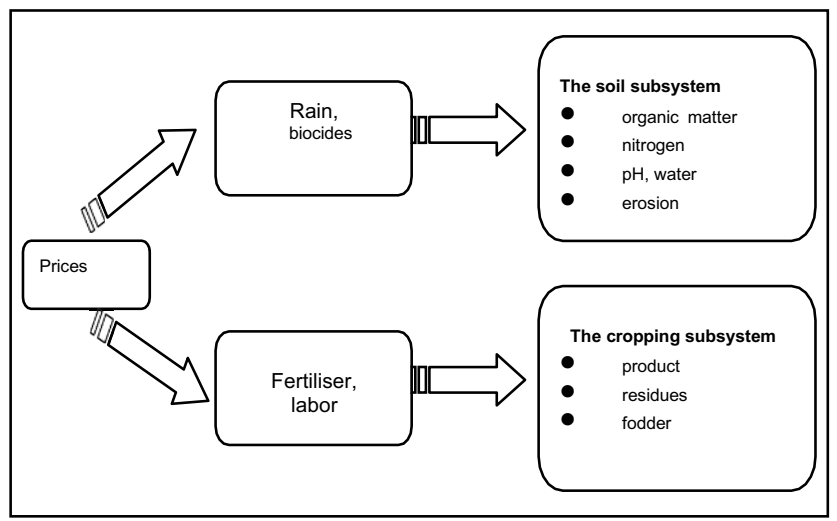

Fig. 1. General structure of model.

Crop production is determined by inputs such as labour and biocides, and the availability of nutrients and water. The availability of nutrients and water is determined by the processes in the soil subsystem, hat depend on soil characteristics, rainfall, residue management, land preparation and the application of fertiliser and animal manure. Income is mainly determined by crop and prices, on the one hand, and, on the other hand, by costs of labour, fertiliser, biocides. In model the following criteria are used to judge the performance:

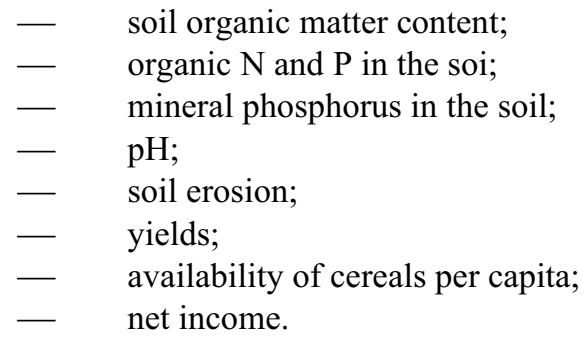

\subsection{Description of the model}

Land preparation and weeding are important prerequisites for a good yield. The extent to which these operations are carried out and their timing are largely determined by the 
availability of labour. The effect of the intensity of land preparation (e.g. number of ploughings), time of sowing and number of weedings may differ per crop.

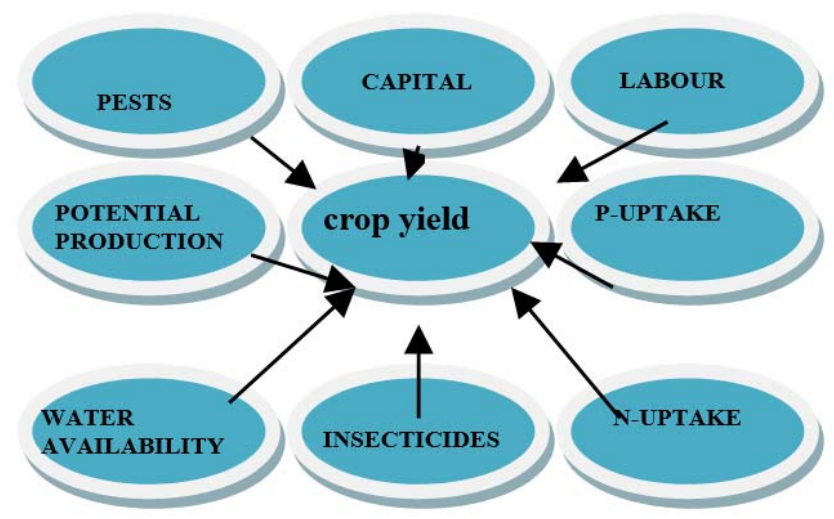

Fig. 2. Schematic presentation of the procedure to determine crop yield

The production of a crop is determined by its potential production, capital, the supply of $\mathrm{N}, \mathrm{P}$ and water, by the effect of pests and diseases and by labour availability (Fig.2).

A delay in sowing reduces the yields by $10 \%$ sometimes estimated the effect of a delay in sowing even at $30 \%$. Based on these considerations, assumptions have been made on the effect of labour shortage. The effects of labour shortage on yield reduction, as used in the model, are presented in Table, where it is determined as:

Table 1. Potential yields of the various crops

\begin{tabular}{|l|l|}
\hline crops & potential yield \\
\hline millet & 3000 \\
maize & 6000 \\
cotton & 2500 (lint plus seed) \\
\hline groundnut & 3000 (unshelled nuts) \\
\hline
\end{tabular}

Labour limited yield land preparation and weeding are important prerequisites for a good yield. The extent to which these operations are carried out and their timing are largely determined by the availability of labour. The effect of the intensity of land preparation (e.g. number of ploughings), time of sowing and number of weedings may differ per crop.

Based on these considerations, assumptions have been made on the effect of labour shortage during the months of May, June and July for various crops. The effects of labour shortage on yield reduction, as used in the model, are presented in Table 2, where cflabour is determined as:

cflabour $=[($ labour avail1 / labour req1) $+($ labour avail2 /labour reqjulle2 $)+($ labour avails3 / labour reqjuiy3)] / 3

where:

labour avail : total labour available (including hired labour) (mandays.month"1)

labour req : total labour required (mandays.month"1) 
Table 2. Effect of labour availability on relative yield

\begin{tabular}{|c|c|}
\hline cflabour & relative yield \\
\hline 0,2 & millet \\
0,4 & maize \\
0,6 & cotton \\
\hline 0,8 & groundnut \\
\hline
\end{tabular}

The effects of pests and diseases on crop production depend upon their incidence, severity and on the susceptibility of the crop.

To take the effect of pests and diseases on the crops into account, a coefficient (cfpest) is introduced expressing the extent of the damage: if there is no damage, the coefficient is 1 and if the crop is completely devastated by the pest or disease the coefficient is 0 .

Nutrient use efficiency is defined as crop production ( $\mathrm{kg}$ dry matter) per $\mathrm{kg}$ nutrient taken up, and can be calculated if the concentrations of the particular nutrient in the seed/fruit, the vegetative above-ground parts and the roots are known as well as the shootroot ratio and the harvest-index (seed/total aboveground dry matter).

The nutrient use efficiency for a particular nutrient (e.g. N) is now calculated as:

$$
\text { N/P limited yield }=\text { N/P-uptake } * \text { N/P use efficiency }
$$

Minimum concentrations in the various parts of the plants are used for calculation of the nutrient use efficiency, as it is assumed that crop production is determined by its most limiting nutrient. This implies that the concentration of that particular nutrient is present in the lowest possible concentration.

As growth during one stage will affect growth in the next stage, the relative yield of the total crop $(\mathrm{Y}$ a / Ym) totai is calculated by multiplying the relative yields per stage:

$$
(Y a / Y m) \text { totai }=(Y a / Y m) \text { jestablishment } *(Y a / Y m) \text { vegetativc* }
$$

Maximum evapo-transpiration (ETm), being the loss of water in the situation where water supply fully meets water requirements of the crop, depends on crop and on weather.

$$
E T m=k c * E T o
$$

$\mathrm{Kc}$ is an empirically determined crop coefficient and represents the influence of the crop and its development stage.

ETo is a reference evapo-transpiration and is assumed to be equal to the evapotranspiration from a short grass cover that is adequately supplied with water. ETo is calculated here according to the radiation method. It has determined as a monthly average.

Availability of nutrients is to a large extent determined by organic matter dynamics, as part of

$\mathrm{N}$ and $\mathrm{P}$ is present in organic form. Moreover, organic matter also influences the availability of water. Therefore, the way organic matter dynamics has been modelled is described, followed by a description of the dynamics of nitrogen and phosphorus.

\subsection{Determinant models and factors within the sustainable development of agriculture}

There are currently many approaches to assess the effectiveness of government support in OECD countries for agricultural producers and agricultural policies. The most authoritative 
of them are four (PEM, SAPIM, AGLINK, GTAP), which are used for the respective purposes by OECD organizations.

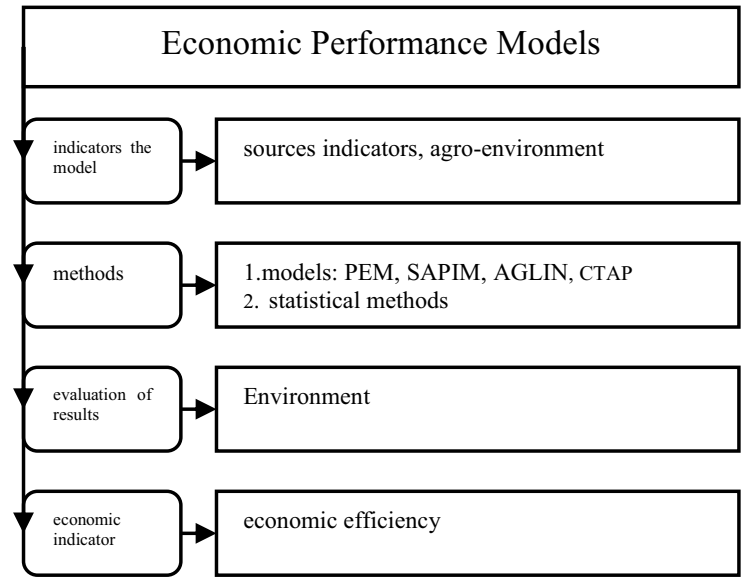

Fig. 3. OECD Economic Performance Models

Based on Figure 3, one can understand the principle of the methodology for assessing the effectiveness of agricultural regulation. Based on the FAO database and using economic indicators for the created models, the economic efficiency of budget allocations is derived.

1) SAPIM. This approach is pragmatic. It simulates at the microeconomic level, including existing farms, in order to increase accuracy. This flexible approach allows detailed modeling of the impacts between agriculture, environment and public policy. However, the disadvantage of this model is that it has a general picture at the national level and cannot cover the full range of changes in the agricultural sector.

2) GTAP (Global Trade Analysis Project). The World Trade Analysis Project is a global network of researchers (mainly from universities, international organizations or national ministries of economics) who conduct quantitative analysis on international economic policy issues, in particular trade policy.

The database describes the flows of bilateral trade, production, consumption and use of intermediate goods and services. It also has so-called satellite databases that are used to estimate greenhouse gas emissions and land use. The software allows you to create predictive models, both at the industry and regional levels.

3) Aglink. The model makes it possible to predict production, consumption, foreign trade, and prices for major agricultural commodities. It contains over 11,000 equations and modules for 39 countries and 19 regions of the world. 90

4) PEM (Policy Evaluation Model). The Political Activity Assessment Model was created as part of the OECD Agricultural Policy Assessment. PEM is a partial equilibrium model that describes the markets for major crops (wheat, grain, oilseeds, rice) and livestock (milk and beef) and their associated markets.

The main indicators of support for agricultural producers make it possible to assess the contribution of different types of support in the framework of the agricultural policy of a particular country and their unions.

In addition to these four, other indicators of support for agricultural producers are used in the world. They all have their own characteristics, strengths and weaknesses.

The most widespread are four of them.

1. The nominal rate of protection (NPR) reflects the increase in all cash receipts from the sale of goods. 
2. Nominal Aid Level (NRA), reflects the increase in all cash receipts, including support not related to the sale of goods.

3. The effective level of protection (ERP), which characterizes the increase in value added from the sale of goods, i.e. takes into account the prices of inputs.

4. Effective Aid Level (ERA), evaluates the increase in value added, both from the sale of a product and from non-sale support. The agrarian sector is in dire need of support and protection of its interests from highly monopolized industries. If we add to this the need of the agricultural sector in the development of social and industrial infrastructure, as well as the need for greening 91 agricultural production, then the need for state support of the agricultural economy is even more obvious.

\section{Empirical results and analysis}

In many countries, the important role of agriculture is recognized as a priority area of the country's economic activity. Every year developed countries increase their budget allocations to support agriculture.

New efficient methods of budget support distribution are emerging. Failure to use government support instruments leads to the degradation of the agricultural sector. In the USA, due to the support of agricultural producers, up to $60 \%$ of their income is formed, in Japan this figure is $75 \%$, in the EU countries - 70-80\%. As an example, Russia's indicators lag significantly behind Western countries and are less than $10 \%$. At the same time, considering the ratio of state support to agricultural GDP, it can be concluded that at this stage the EU countries and the United States are unattainable for Russia.

The problem of the amount of financing of agricultural provision of the economy is possible is one of the control of the important problems in this sector was the budget. For several years now, agriculture has been responding to the identified main related problems, which, however, are directly related to the growth through consumption of agricultural products produced abroad.

In the course of the analysis and modelling, we found that the distinctive features of agriculture include:

-low profitability of agricultural activity, which is a consequence of difficult natural and climatic conditions, high tariffs for electricity and fuel, which do not allow an agricultural producer to receive sufficient profit for the development of production;

- low level of material and technical base;

- due to the low level of wages of the rural population, urbanization occurs, during which the able-bodied population moves to the city in search of a better life.

In the course of the analysis, the volume of grain sown areas is calculated by the formula:

$$
S i=S i-1 * A p+10000 * A p e c
$$

where Ap is the state support coefficient equal to

$$
A p=0.0575 * \ln (M+T) * K
$$

$\mathrm{M}$ - expenses for land reclamation, $\mathrm{T}$ - expenses for technological modernization, $\mathrm{K}$ personnel growth.

The yield is calculated according to the formula:

$$
m=m i * A p(u r)
$$


in turn, $\mathrm{m}$ is the yield, Ap (ur) is the coefficient of state support for land reclamation and seed production.

To calculate the gross harvest, the formula is the same for all types of agricultural crops:

$$
V i=S i * m i
$$

For each crop represented in the model, the calculation is carried out in accordance with the formulas presented in paragraph 3.2.

According to the calculations, we get the correlation graph:

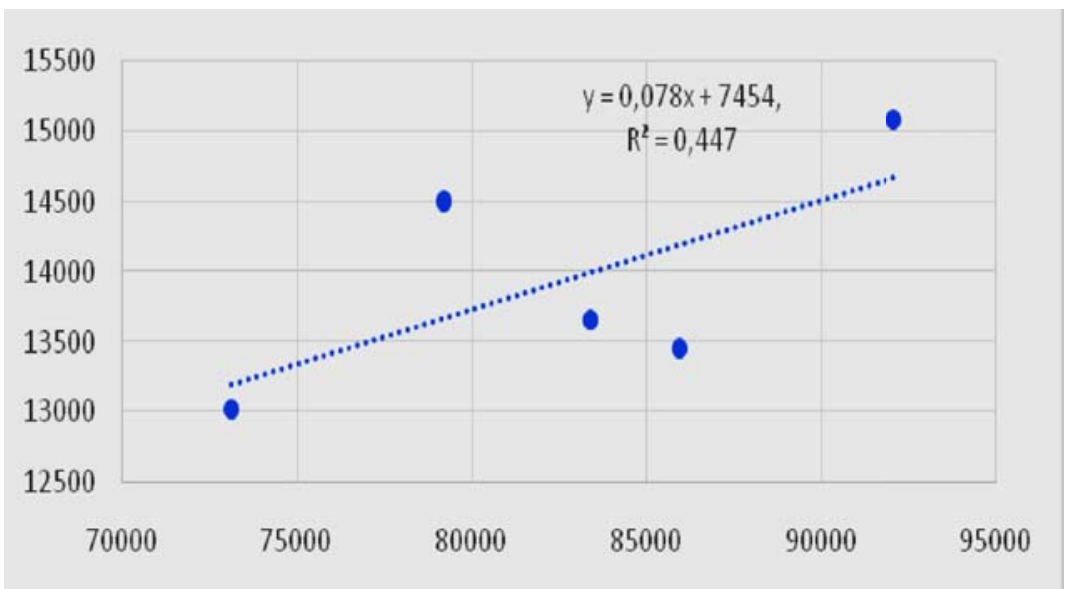

Fig. 4. Regression Relationship Between Land Reclamation Costs and Yields

The figure shows a direct linear relationship between the costs of land reclamation and productivity

From the presented regression equation $y=0.0784 x+7454.2$ it can be concluded that with an increase in yield at a cost of 1 billion rubles. reclamation expenses increase on average by $78.4 \mathrm{mln}$.

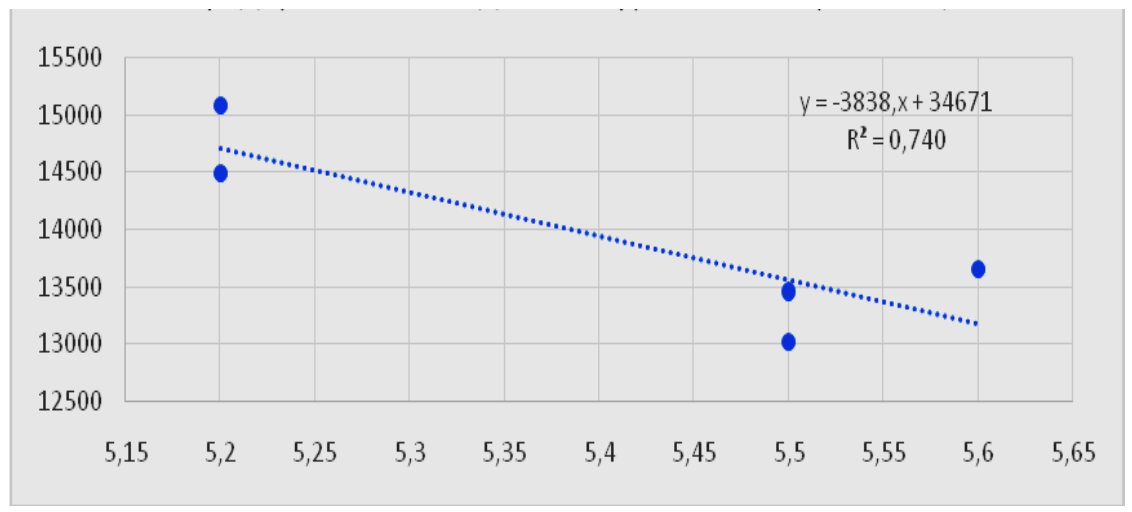

Fig. 5. Regression relationship between the growth of personnel in agriculture and the gross harvest of agricultural crops

From the presented regression equation, we can conclude that with an increase in unemployment in the agricultural sector by $1 \%$, the value of the gross harvest of agricultural crops decreases on average by 3838.1 billion roubles. 


\section{Conclusion}

In this article, we have identified models and factors of economic optimization, which allows us to analyze external and internal factors influencing the development of agriculture, based on quantitative indicators with structured qualitative characteristics.

All assessed indicators are formally described by mathematical variables. Models and regressions characterize the semantics of the meanings of linguistic numbers and mathematical calculations.

Based on the use of the constructed mathematical model and the analysis carried out on the basis of the basic formulas, a factorial experiment was carried out, the processing of the results of which made it possible to include in the analytical form the relationship between the input and output values. The results of the analysis allow on a formalized basis to take into account external and internal pathogens and negative factors of influence on agriculture, used in the decision-making process for the sustainable development of agriculture.

\section{References}

1. N. Natocheeva, A. Borodin, N. Rud N., G. Kutsuri, M. Zholamanova, N. Namitulina, Entrepreneurship and Sustainability,7(2),1654 (2019)

2. S. Ziyadin, S. Suieubayeva, A. Utegenova, Digital Transformation in Business. Springer, Cham (2020)

3. G. Mutanov, S. Ziyadin, E3S Web of Conferences 135, 04056 (EDP Sciences 2019)

4. Richard Thornton Smith, Cosmos, Earth and Nutrition: The Biodynamic Approach to Agriculture (2009)

5. J. Malat, J. Velebil, J. Bradna, Agronomy Research 16(2), 534 (2018)

6. M. Mimra, M. Kavka, R. Renfus, R, Agronomy Research 14(S1), 1180 (2016)

7. G. Mutanov, S. Ziyadin, E3S Web of Conferences, 135, 04056 (EDP Sciences 2019)

8. J. Dombey, E. Tóth-Laufer, Reducing computational requirements in fuzzy control of the Mamdani type. ActaPolytechnicaHungarica. (2020) 